\title{
Presepsin values and Prognostic Nutritional Index predict mortality in intensive care unit patients with sepsis: a prospective observational study
}

Yuichiro Shimoyama ( $\sim$ icu003@osaka-med.ac.jp )

Osaka Medical College

Osamu Umegaki

Osaka Medical College: Osaka Ika Daigaku

Noriko Kadono

Osaka Medical College: Osaka Ika Daigaku

Toshiaki Minami

Osaka Medical College: Osaka Ika Daigaku

\section{Research}

Keywords: presepsin, sepsis, sepsis-3 definition, inflammation-based prognostic scores, mortality

Posted Date: September 24th, 2020

DOI: https://doi.org/10.21203/rs.3.rs-80606/v1

License: @ (i) This work is licensed under a Creative Commons Attribution 4.0 International License. Read Full License 


\section{Abstract \\ Background}

Sepsis is a major cause of mortality for critically ill patients. This study aimed to determine whether presepsin values can predict mortality in patients with sepsis.

\section{Methods}

A total of 83 adult patients diagnosed with sepsis were prospectively examined. Presepsin values were measured immediately after ICU admission and on Days 2, 3, and 5 after ICU admission. Glasgow Prognostic Score, neutrophil to lymphocyte ratio, platelet to lymphocyte ratio, Prognostic Index, and Prognostic Nutritional Index were also determined at baseline. For category classification, total scores were calculated (hereafter, "inflammation-presepsin scores [iPS]") as follows: a score of 1 was assigned if the presepsin value and inflammation-based prognostic scores at baseline were above cut-offs determined by receiver operating characteristic (ROC) curve analysis for 28-day mortality; a score of 0 was assigned if they were below the cut-offs (total score range, 0-2 points). Presepsin values, inflammation-based prognostic scores, and iPS were compared between non-survivors and survivors.

\section{Results}

ROC curve analysis, Log-rank test, and multivariate analysis identified presepsin values and Prognostic Nutritional Index as predictors of mortality in sepsis patients. Presepsin value on Day 1 was a predictor of early mortality, i.e., death within 7 days of ICU admission; ROC curve analysis revealed an AUC of 0.84 , sensitivity of $89 \%$, and specificity of $77 \%$; multivariate analysis showed an OR of 1.0007 , with a $95 \% \mathrm{Cl}$ of $1.0001-1.0013(p=0.0320)$.

\section{Conclusions}

Presepsin value was a predictor of mortality in sepsis patients. In particular, the presepsin value on Day 1 is useful for predicting early mortality. In the context of 28-day mortality, Prognostic Nutritional Index was found to predict mortality in sepsis patients.

\section{Background}

The Third International Consensus Definitions Task Force (Sepsis-3) updated their criteria for defining sepsis in 2016 [1]. Sepsis is defined as a syndrome that can lead to lethal organ dysfunction caused by a dysregulated host response to infection. Despite efforts to improve early recognition and advances in antibiotics, sepsis remains a major cause of mortality in critically ill patients [2]. Sepsis can evolve to lethal multiorgan failure, for which an increase of $\geq 2$ in the Sequential Organ Failure Assessment (SOFA) 
score is associated with an in-hospital mortality rate as high as $10 \%$ [1]. To reduce its high mortality rate, early goal-directed management, i.e., early recognition of severe sepsis, and early initiation of aggressive and supportive therapy are crucial $[3,4]$. To this end, several biomarkers have been adopted in clinical settings. Procalcitonin (PCT) is a diagnostic marker used for bacterial sepsis with the highest specificity and is widely adopted in clinical settings. However, PCT values can be elevated by non-septic conditions such as severe trauma, invasive surgery, and critical burn injuries, which can in turn lead to false-positive results [5-7]. Presepsin, a subtype of soluble CD14 (CD14-ST), is a 13-kDa truncated N-terminal fragment of CD14 [8] which is released into the circulation during monocyte activation upon the recognition of lipopolysaccharide from infectious agents [9]. Presepsin values are correlated with severity of sepsis [10] and are useful for predicting prognosis and monitoring the disease course for sepsis $[9,11]$. Presepsin can be measured in less than 17 minutes by a chemiluminescent enzyme immunoassay (CLEIA) with a compact fully automated immunoanalyzer (PATHFAST ${ }^{\circledR}$; Mitsubishi Chemical Medience Corporation, Tokyo, Japan) [12] and has been used as a biomarker to diagnose bacterial sepsis.

Inflammation-based prognostic scores, including the Glasgow Prognostic Score (GPS; based on serum Creactive protein (CRP) and albumin levels), neutrophil to lymphocyte ratio (NLR), platelet to lymphocyte ratio (PLR), Prognostic Nutritional Index (PNl; based on albumin and lymphocyte counts), and the Prognostic Index (Pl; based on serum CRP and white blood cell counts), have been adopted as significant prognostic biomarkers for several types of cancer [13]. However, no study has assessed the association of mortality with presepsin values alone or in combination with inflammation-based prognostic scores (i.e., GPS, NLR, PLR, PNI, and PI) in patients with sepsis as defined according to the Sepsis-3 definition. Accordingly, the present study aimed to test the following hypotheses: 1) presepsin is a useful predictor for early and long-term mortality in sepsis patients; 2) presepsin values are superior to inflammationbased prognostic scores for predicting mortality, and; 3 ) the ability to predict mortality can be improved by combining presepsin values and inflammation-based prognostic scores, compared to using presepsin values alone.

\section{Methods}

\section{Patients and study design}

This single-center prospective study was conducted in a 16-bed ICU. The study protocol was approved by the Ethics Committee of Osaka Medical College (Osaka, Japan). In total, 83 adult patients older than 18 years who were diagnosed with sepsis according to the Sepsis-3 definition [1] and admitted to the ICU were prospectively examined from December 2017 to August 2019. Written informed consent was obtained from all patients enrolled in this study or their families. Patients who exhibited clinical evidence of anti-inflammatory conditions were excluded, including those undergoing immunosuppressive therapy (e.g., chemotherapy, chronic steroid use, autoimmune disease treatment) within one month of the study.

Arterial blood samples were collected from each patient and presepsin values were measured immediately after ICU admission (baseline) and on Days 2, 3, and 5 after ICU admission. Mortality was 
categorized as 28-, 60-, 90-, and 180-day mortality.

GPS, NLR, PLR, PI, and PNI were examined at baseline. For category classification, total scores were calculated (hereafter, "inflammation-presepsin scores [iPS]") as follows: a score of 1 was assigned if the presepsin value and inflammation-based prognostic scores at baseline were above cut-offs determined by receiver operating characteristic (ROC) curve analysis for 28-day mortality; a score of 0 was assigned if they were below the cut-offs (total score range, 0-2 points). As an example of nomenclature, the combination of presepsin value and NLR is presented as "iPS-NLR." Presepsin values, inflammationbased prognostic scores, iPS, and changes $(\Delta)$ in presepsin values relative to baseline values at each sampling point were compared between survivors and non - survivors.

\section{Laboratory assessments}

Arterial blood samples collected from sepsis patients at each sampling point were immediately subjected to presepsin measurement. Presepsin concentration was measured by CLEIA (PATHFAST $®$; Mitsubishi Chemical Medience Corporation, Tokyo, Japan) [12]. Assay results were obtained within 17 minutes. This assay can detect systemic infection (sepsis) within the range of 300 to $500 \mathrm{pg} / \mathrm{ml}$.

\section{Statistical analysis}

Categorical data are reported as percentages and compared using Fisher's exact test. Continuous data are reported as medians with inter-quartile ranges and compared using the Mann-Whitney $\mathrm{U}$ test. ROC curves were generated for presepsin values, inflammation-based prognostic scores, iPS, and $\Delta$ presepsin, and areas under the curve (AUCs), cut-off values, sensitivities, and specificities were calculated. Presepsin values, inflammation-based prognostic scores, iPS, $\triangle$ presepsin, SOFA, and quick SOFA (qSOFA) (with P< 0.05 in univariate analysis) were examined further by multivariate logistic regression analysis for predicting mortality associated with sepsis. $\mathrm{P}<0.05$ was considered statistically significant. JMP software version 11.0.0 (SAS Institute Inc., NC, USA) was used for all statistical analyses.

\section{Results}

Baseline characteristics of patients are shown in Table 1. No significant differences in age or sex were observed among sepsis patients. Presepsin values of survivors were higher than those of non-survivors (Figs. 1, 2).

ROC curve analyses (Table 2) revealed the following cut-off values: 28-day mortality: 1340.0 (pg/ml) for presepsin on Day 1 (AUC, 0.81; sensitivity, 78\%; specificity, 75\%), 1163.0 (pg/ml) for presepsin on Day 2 (AUC, 0.80; sensitivity, 91\%; specificity, 67\%); 1819.0 (pg/ml) for presepsin on Day 3 (AUC, 0.91; sensitivity, $86 \%$; specificity, $83 \%) ; 3011.0$ (pg/ml) for presepsin on Day 5 (AUC, 0.91 ; sensitivity, $86 \%$; specificity, 100\%); 680.0 (pg/ml) for $\Delta$ presepsin Day 3-Day 1 (AUC, 0.72; sensitivity, 57\%; specificity, 92\%); 22.73 (pg/ml) for PNI (AUC, 0.73; sensitivity, 67\%; specificity, 75\%); 
$1.00(\mathrm{pg} / \mathrm{ml})$ for iPS-GPS (AUC, 0.72; sensitivity, 100\%; specificity, 47\%); 2.00 (pg/ml) for iPS-NLR (AUC, 0.72; sensitivity, $50 \%$; specificity, $86 \%$ ); 1.00 (pg/ml) for iPS-PLR (AUC, 0.73 ; sensitivity, $94 \%$; specificity, 41\%), 60-day mortality: 1340.0 (pg/ml) for presepsin on Day 1 (AUC, 0.78 ; sensitivity, $71 \%$; specificity, $75 \%), 1163.0$ (pg/ml) for presepsin on Day 2 (AUC, 0.76; sensitivity, 85\%; specificity, 67\%), 1156.0 (pg/ml) for presepsin on Day 3 (AUC, 0.83; sensitivity, 90\%; specificity, 78\%), 3011.0 (pg/ml) for presepsin on Day 5 (AUC, 0.77; sensitivity, 67\%; specificity, $100 \%$ ), and 1.00 for iPS-NLR (AUC, 0.71 ; sensitivity, 81\%; specificity, 52\%), 90-day mortality: 1340.0 (pg/ml) for presepsin on Day 1 (AUC, 0.76 ; sensitivity, 65\%; specificity, 75\%), 1163.0 (pg/ml) for presepsin on Day 2 (AUC, 0.73; sensitivity, 73\%; specificity, 66\%), 1156.0 (pg/ml) for presepsin on Day 3 (AUC, 0.83; sensitivity, 91\%; specificity, 81\%), $1399.0(\mathrm{pg} / \mathrm{ml})$ for presepsin on Day 5 (AUC, 0.78; sensitivity, 70\%; specificity, 79\%), and 180-day mortality: 1336.0 (pg/ml) for presepsin on Day 1 (AUC, 0.77 ; sensitivity, 68\%; specificity, 75\%), 1163.0 (pg/ml) for presepsin on Day 2 (AUC, 0.75; sensitivity, 76\%; specificity, 69\%), 1156.0 (pg/ml) for presepsin on Day 3 (AUC, 0.85; sensitivity, 92\%; specificity, 83\%), 1313.0 (pg/ml) for presepsin on Day 5 (AUC, 0.78; sensitivity, 73\%; specificity, 74\%), 390.0 (pg/ml) for $\Delta$ presepsin Day 3-Day 1 (AUC, 0.73; sensitivity, 58\%; specificity, 91\%), $1.00(\mathrm{pg} / \mathrm{ml})$ for iPS-GPS (AUC, 0.71 ; sensitivity, 96\%; specificity, $51 \%$ ).

Log-rank test also revealed presepsin, $\Delta$ presepsin Day 2-Day 1, $\Delta$ presepsin Day 3-Day 1, PNI, iPS-GPS, iPS-NLR, iPS-PI, and iPS-PLR as independent predictors of mortality in sepsis patients (Table 3 ).

Presepsin values, inflammation-based prognostic scores, iPS, $\triangle$ presepsin, SOFA, and qSOFA (with P< 0.05 in univariate analysis) were examined further by multivariate logistic regression analysis for mortality (Table 4). Presepsin on Day 1 was found to be a significant independent predictor of 28-day mortality $(\mathrm{OR}, 1.0025 ; 95 \% \mathrm{Cl}, 1.00005-1.00497 ; \mathrm{p}=0.046), 60$-day mortality $(\mathrm{OR}, 1.0027 ; 95 \% \mathrm{Cl}, 1.00025-$ 1.00508; $p=0.030)$, 90-day mortality $(\mathrm{OR}, 1.0027 ; 95 \% \mathrm{Cl}, 1.00025-1.00508 ; \mathrm{p}=0.030)$, and 180-day mortality (OR, $1.0027 ; 95 \% \mathrm{Cl}, 1.00025-1.00508 ; \mathrm{p}=0.030)($ Table 5$)$.

Furthermore, we investigated whether presepsin value on Day 1 is useful for predicting early mortality (i.e., death within 7 days of ICU admission) in sepsis patients. ROC curve analyses (Fig. 3, Tables 6, 7) revealed the following cut-off values: death within 7 days of ICU admission: $1373.0(\mathrm{pg} / \mathrm{ml})$ for presepsin on Day 1 (AUC, 0.84; sensitivity, 89\%; specificity, 77\%), 22.73 (pg/ml) for PNI (AUC, 0.70; sensitivity, 67\%; specificity, 77\%), 2.0 (pg/ml) for iPS-GPS (AUC, 0.76; sensitivity, 56\%; specificity, 91\%), 2.0 (pg/ml) for iPSNLR (AUC, 0.79; sensitivity, 56\%; specificity, 88\%), 2.0 (pg/ml) for iPS-PLR (AUC, 0.80; sensitivity, 44\%; specificity, $93 \%$ ), and $1.0(\mathrm{pg} / \mathrm{ml})$ for iPS-PI (AUC, 0.74 ; sensitivity, $100 \%$; specificity, $55 \%$ ). For death after 7 days since ICU admission, the cut-off was 1152.0 (pg/ml) for presepsin on Day 1 (AUC, 0.71; sensitivity, 71\%; specificity, 64\%). Presepsin on Day 1 was found to be a significant independent predictor of death within 7 days of ICU admission by multivariate logistic regression analysis $(\mathrm{OR}, 1.0007 ; 95 \% \mathrm{Cl}, 1.0001-$ 1.0013; $p=0.0320)($ Table 8$)$.

\section{Discussion}


Severe sepsis is a syndrome accompanied by lethal organ dysfunction due to dysregulated host responses to infection, and is associated with a mortality rate higher than $50 \%$ [14]. Sepsis initiates the activation of both pro- and anti-inflammatory responses [15], both of which are amplified by nonimmunologic pathways including cardiovascular, neuronal, autonomic, hormonal, bioenergetic, metabolic, and coagulation pathways [16-18]. Early diagnostic and prognostic biomarkers with high sensitivity and specificity are crucial for the early identification of high-risk sepsis patients. PCT is a diagnostic marker used for bacterial sepsis with the highest specificity and widely used in clinical settings, but can give false-positive results as its values can increase even during non-septic conditions (e.g., severe trauma, invasive surgical procedure, critical burn injuries) [5-7]. These false-positive results may be obstructive toward obtaining information on whether or not to initiate aggressive and supportive therapy in sepsis patients or other critically ill patients within the first few hours after ICU admission. Presepsin, a subtype of CD14-ST, is secreted from granulocytes by infectious stimuli in an animal sepsis model [19] and can thus be used as a highly specific biomarker for diagnosing bacterial sepsis. Presepsin values are useful for diagnosing early stage sepsis in emergent patients and are independently associated with the degree of organ dysfunction, coagulation disorders, and ICU mortality [20,21].

The present study demonstrated that presepsin is a better predictor of mortality in septic patients than SOFA or qSOFA (Tables 2, 3, 5, 6 and 8). Furthermore, the AUC of presepsin for predicting mortality showed a range of $0.73-0.91$, indicating a higher predictive ability than that observed for iPS and inflammation-based prognostic scores alone (Table 2). AUC values of presepsin for predicting 28-day mortality were all higher than each of the presepsin AUC values for 60-, 90-, and 180-day mortality. Moreover, multivariate analysis revealed that only the presepsin value on Day 1 predicted mortality rates. Collectively, these findings suggest that the AUC of presepsin on Day 1 might be effective in predicting early mortality (Tables 2,5$)$.

We also investigated the ability of presepsin values on Day 1 to predict early mortality (i.e., death within 7 days of ICU admission). The AUC of presepsin on Day 1 to predict death within 7 days of ICU admission was 0.84 , suggesting a greater predictive ability than that observed for presepsin on Day 1 for death after 7 days since ICU admission and inflammation-based prognostic scores alone, iPS, SOFA, and qSOFA for death within 7 days of ICU admission (Tables 6,7). Multivariate logistic regression analysis for mortality found the presepsin value on Day 1 to be a significant independent predictor of death within 7 days of ICU admission (OR, 1.0007; $95 \% \mathrm{Cl}, 1.0001-1.0013 ; \mathrm{p}=0.032$; Table 8). Ulla et al. reported that a higher level of presepsin at presentation in the emergency department was correlated to 60-day mortality. [22] Masson et al. found that presepsin levels measured at the time of presentation among patients with severe sepsis or septic shock were higher in non-survivors than in survivors [23], and our findings were consistent with these results. Masson et al. also found significantly higher presepsin levels on Days 2 and 7 in non-survivors when compared with survivors. In the present study, presepsin levels among nonsurvivors were significantly higher on all days relative to survivors (Figs. 1, 2).

In the present study, presepsin cut-off values for predicting each designation of mortality were higher than previously reported cut-offs for diagnosing either sepsis (300 to $500 \mathrm{pg} / \mathrm{ml}$ ) or severe sepsis (500 to 
$1000 \mathrm{pg} / \mathrm{ml})[24,25]$. Klouche reported that a cut-off presepsin value for mortality in sepsis patients was $1926 \mathrm{pg} / \mathrm{ml}$ [26]. These results suggest the need to adopt a higher presepsin cut-off value for predicting mortality associated with sepsis.

The presepsin values for $\Delta$ Day 3-Day 1 in 28- or 180-day mortality showed higher specificity for predicting 28- or 180-day mortality compared with presepsin values on Days 1,2, 3, and 5 alone for all mortality (Table 2). These findings suggest that $\Delta$ presepsin Day 3-Day 1 may be useful as a "rule in" test for predicting mortality. Log-rank test also revealed $\Delta$ presepsin Day 3-Day 1 and $\Delta$ presepsin Day 2-Day 1 to be independent predictors of mortality in septic patients (Table 3). Presepsin values on Days 3 and 5 had higher AUCs for predicting 28-day mortality than the presepsin values on Days 1 and 2 (Table 2). These results suggest the importance not only of measuring presepsin values at the time of ICU admission but also monitoring its changes on Day 2 and thereafter following ICU admission, in order to predict mortality in sepsis patients.

The AUC, sensitivity, and specificity of PNI for predicting 28 -day mortality were $0.73,70 \%$, and $80 \%$, respectively, corresponding to a greater AUC than that observed for inflammation-based prognostic scores alone, iPS, SOFA, and qSOFA (Table 2). Log-rank test revealed PNI as an independent predictor of all mortality in sepsis patients (Table 3). Previously, we found that NLR is superior to other inflammationbased prognostic scores in predicting mortality among patients with gastrointestinal perforation and pneumonia $[27,28]$. With regard to 28-day mortality, however, the present study found PNI to be a predictor of mortality in sepsis patients. Pinato et al. [29] reported that PNI is a predictor of poor overall survival in patients with hepatocellular carcinoma. In the Albumin Italian Outcome Sepsis trial, albumin replacement did not improve survival at 28 and 90 days among patients with severe sepsis or septic shock [30]. However, our findings suggest that, of the many variables that can be investigated for assessing inflammation, hypoalbuminemia and lymphocytopenia (albumin and lymphocyte counts used to calculate $\mathrm{PNI}$ ) are important variables for predicting mortality in sepsis patients. In the context of predicting 28-day mortality, PNI shows a lower AUC than that of presepsin, but in clinical environments where presepsin values cannot be measured, PNI at presentation may be useful for determining 28-day mortality. PNI can be obtained at low cost and rapidly, and provides crucial information needed to begin aggressive and supportive therapy in sepsis patients within the first few hours of ICU admission.

No previous study has assessed the association between presepsin values, $\mathrm{PNI}$, and mortality in patients with sepsis according to the Sepsis-3 definition. Our findings are novel in this respect. Further studies will be needed to clarify how presepsin values and PNI can predict mortality in sepsis patients.

This study has several limitations. First, the present study was a single-center study with a small cohort. Second, we used a single biomarker, and no comparisons were made with other biomarkers. Third, presepsin values increase with declining renal function [31]. Thus, the diagnostic accuracy of presepsin values may be influenced by kidney function.

\section{Conclusions}


Presepsin was found to be a predictor of mortality in patients with sepsis. Presepsin is a better predictor of mortality in sepsis patients than SOFA or qSOFA. In particular, the presepsin value on Day 1 is useful for predicting early mortality (i.e., death within 7 days of ICU admission). In addition to measuring presepsin values at the time of ICU admission, any changes in these values on Day 2 and thereafter following ICU admission should be monitored in order to predict mortality in sepsis patients. In the context of 28-day mortality, PNI was found to be a predictor for mortality in sepsis patients. Further studies aimed at understanding the exact role of presepsin values and PNI in predicting mortality in sepsis patients are warranted.

\section{Abbreviations}

GPS: Glasgow Prognostic Score

CRP: C-reactive protein (CRP)

NLR: neutrophil to lymphocyte ratio

PLR: platelet to lymphocyte ratio

PNI: Prognostic Nutritional Index

PI: Prognostic Index

ROC: Receiver operating characteristic

AUC: area under the curve

\section{Declarations}

\section{Ethics approval and consent to participate:}

Written informed consent was obtained from all patients enrolled in this study or their families. The study protocol was approved by the Ethics Committee of Osaka Medical College (Osaka, Japan).

\section{Consent for publication:}

Written informed consent was obtained from all patients enrolled in this study or their families.

\section{Availability of data and materials:}

Datasets of the present study are available from the corresponding author upon reasonable request.

\section{Competing interests:}




\section{Funding:}

This work was not supported by any funding source. Support was provided solely from institutional and/or departmental sources.

\section{Author's contributions:}

YS designed the study, performed the data collection and statistical analysis, and wrote the first draft of the manuscript; $\mathrm{OU}, \mathrm{NK}$, and TM designed the study and performed the manuscript revision. All authors read and approved the final manuscript.

\section{Acknowledgements:}

Not applicable.

\section{References}

1. Singer M, Deutschman CS, Seymour CW, Shankar-Hari M, Annane D, Bauer M, et al. The third international consensus definitions for sepsis and septic shock (Sepsis-3). JAMA. 2016;315:801-10.

2. Vincent JL, Sakr Y, Sprung CL, Ranieri VM, Reinhart K, Gerlach H, et al. Sepsis in European intensive care units: results of the SOAP study. Crit Care Med. 2006;34:344-53.

3. Angus DC, van der Poll T. Severe sepsis and septic shock. N Engl J Med. 2013;369:840-51.

4. Dellinger RP, Levy MM, Rhodes A, Annane D, Gerlach H, Opal SM, et al. Surviving Sepsis Campaign Guidelines Committee including the Pediatric Subgroup: Surviving Sepsis Campaign: International Guidelines for Management of Severe Sepsis and Septic Shock 2012. Crit Care Med. 2013;41:580637.

5. Pierrakos C, Vincent J-L. Sepsis biomarkers: a review. Crit Care. 2010;14:R15.

6. Wacker C, Prkno A, Brunkhorst FM, Schlattmann P. Procalcitonin as a diagnostic marker for sepsis: a systematic review and meta-analysis. Lancet Infect Dis. 2013; 13: 426-35.

7. Kibe S, Adams K, Barlow G. Diagnostic and prognostic biomarkers of sepsis in critical care. J Antimicrob Chemother. 2011;66(Suppl 2):ii33-40.

8. Shirakawa K, Naitou K, Hirose J, Takahashi T, Furusako S: Presepsin (sCD14-ST): development and evaluation of one-step ELISA with a new standard that is similar to the form of presepsin in septic patients. Clin Chem Lab Med 2011, 49:937-939.

9. Shozushima T, Takahashi G, Matsumoto N, Kojika M, Okamura Y, Endo S: Usefulness of presepsin (sCD14-ST) measurements as a marker for the diagnosis and severity of sepsis that satisfied 
diagnostic criteria of systemic inflammatory response syndrome. J Infect Chemother 2011, 17:764769.

10. Behnes M, Bertsch T, Lepiorz D, Lang S, Trinkmann F, Brueckmann M, et al. Diagnostic and prognostic utility of soluble CD14 subtype (presepsin) for severe sepsis and septic shock during the first week of intensive care treatment. Crit Care. 2014;18(5):507.

11. Endo S, Suzuki Y, Takahashi G, Shozushima T, Ishikura H, Murai A, et al. Usefulness of presepsin in the diagnosis of sepsis in a multicenter prospective study. J Infect Chemother. 2012; 18: 891-7.

12. Okamura Y, Yokoi H. Development of a point-of-care assay system for measurement of presepsin (sCD14-ST). Clin Chim Acta. 2011; 412: 2157-61.

13. Kinoshita A, Onoda H, Imai N, A Iwaku, M Oishi, N Fushiya, et al: Comparison of the prognostic value of inflammation-based prognostic scores in patients with hepatocellular carcinoma. Br J Cancer 2012; 107:988-993

14. Angus DC, Linde-Zwirble WT, Lidicker J, Clermont G, Carcillo J, Pinsky MR: Epidemiology of severe sepsis in the United States: analysis of incidence, outcome and associated costs of care. Crit Care Med 2001, 29:1303-1310.

15. Hotchkiss RS, Monneret G, Payen D. Sepsis-induced immunosuppression: from cellular dysfunctions to immunotherapy. Nat Rev Immunol. 2013; 13(12):862-874.

16. Levy MM, Fink MP, Marshall JC, Abraham E, Angus D, Cook D, Cohen J, Opal SM, Vincent JL, Ramsay G, International Sepsis Definitions Conference: SCCM/ESICM/ACCP/ATS/SIS international sepsis definitions conference. Intensive Care Med 2001, 2003(29):530-538.

17. Calandra T, Cohen J: The international sepsis forum consensus conference on definitions of infection in the intensive care unit. Crit Care Med 2005, 33:1538-1548.

18. Tunkel AR, Hartman BJ, Kaplan SL, Kaufman BA, Roos KL, Scheld WM, Whitley RJ: Practice guidelines for the management of bacterial meningitis. Clin Infect Dis 2004, 39:1267-1284.

19. Naitoh K, Shirakawa K, Hirose J, Nakamura M, Takeuchi T, Hosaka Y, Furusako S: The new sepsis marker, SCD14-ST (PRESEPSIN): induction mechanism in the rabbit sepsis models. Crit Care 2010, 14:P19.

20. Liu B, Chen Y-X, Yin Q, Zhao Y-Z, Li C-S. Diagnostic value and prognostic evaluation of Presepsin for sepsis in an emergency department. Crit Care. 2013; 17(5):R244.

21. Masson S, Caironi P, Fanizza C, Thomae R, Bernasconi R, Noto A, et al. Circulating presepsin (soluble CD14 subtype) as a marker of host response in patients with severe sepsis or septic shock: data from the multicenter, randomized ALBIOS trial. Intensive Care Med. 2015; 41:12-20.

22. Ulla M, Pizzolato E, Lucchiari $M$, et al. Diagnostic and prognostic value of presepsin in the management of sepsis in the emergency department: a multicenter prospective study. Crit Care. 2013; 17(4):R168.

23. Masson S, Caironi P, Spanuth E, et al. Presepsin (soluble CD14 subtype) and procalcitonin levels for mortality prediction in sepsis: data from the Albumin Italian Outcome Sepsis trial. Crit Care. 2014; 18(1):R6. 
24. C. Chenevier-Gobeaux, D. Borderie, N. Weiss, T. Mallet-Coste and Y.-E. Claessens, "Presepsin (sCD14ST), an innate immune response marker in sepsis," Clinica chimica acta; international journal of clinical chemistry, vol. 450, p. 97-103, 2015.

25. R. Carpio, J. Zapata, E. Spanuth and G. Hess, "Utility of presepsin (sCD14-ST) as a diagnostic and prognostic marker of sepsis in the emergency department," Clinica chimica acta; international journal of clinical chemistry, vol. 450, p. 169-175, 2015.

26. Kada Klouche, Jean Paul Cristol, Julie Devin, Vincent Gilles, Nils Kuster, Romaric Larcher, Laurent Amigues, Philippe Corne, Olivier Jonquet, Anne Marie Dupuy. Diagnostic and prognostic value of soluble CD14 subtype (Presepsin) for sepsis and community-acquired pneumonia in ICU patients. Ann Intensive Care. 2016 Dec; 6(1):59. doi: 10.1186/s13613-016-0160-6. Epub 2016 Jul 7.

27. Shimoyama Y, Umegaki O, Agui T, Noriko Kadono, Toshiaki Minami. Neutrophil to lymphocyte ratio and platelet to lymphocyte ratio are superior to other inflammation-based prognostic scores in predicting the mortality of patients with gastrointestinal perforation. JA Clinical Reports 2017; 3:49

28. Shimoyama Y, Umegaki O, Inoue S, Tomoyuki Agui, Noriko Kadono, Toshiaki Minamiet. The neutrophil to lymphocyte ratio is superior to other inflammation-based prognostic scores in predicting the mortality of patients with pneumonia. Acta Med. 2018; 72:591-3

29. Pinato DJ, North BV, Sharma R. A novel, externally validated inflammation-based prognostic algorithm in hepatocellular carcinoma: the prognostic nutritional index (PNI). Br J Cancer. 2012; 106: $1439-1445$

30. Caironi P, Tognoni G, Masson S, Fumagalli R, Pesenti A et al. Albumin replacement in patients with severe sepsis or septic shock. N Engl J Med. 2014; 370:1412-1421

31. Nagata T, Yasuda $Y$, Ando M, Abe T, Katsumo T, Kato $S$, Tsuboi N, et al. Clinical impact of kidney function on Presepsin levels. PLoS ONE. 2015; 10(6):e0129159. doi:10.1371/journal.pone.0129159.

\section{Tables}


Table 1. Baseline demographic characteristics

\begin{tabular}{|c|c|c|}
\hline Variable & \multicolumn{2}{|c|}{$\mathrm{n}=83$} \\
\hline Age (years) & 74.0 & $(65.5-78.5)$ \\
\hline Sex (male) $(\%)$ & 51.0 & (61.4) \\
\hline Cancer (\%) & 40.0 & $(48.2)$ \\
\hline Coronary artery disease (\%) & 4.0 & $(4.8)$ \\
\hline Diabetes mellitus (\%) & 10.0 & $(12.0)$ \\
\hline Hypertension (\%) & 21.0 & $(25.3)$ \\
\hline Albumin (g/dL) & 2.3 & $(1.8-3.0)$ \\
\hline CRP (mg/dL) & 10.4 & $(3.7-17.5)$ \\
\hline WBC $\left(\times 10^{9} \Gamma^{1}\right)$ & 10.9 & $(5.4-15.4)$ \\
\hline Neutrophil count $\left(\times 10^{9} \Gamma^{1}\right)$ & 8.7 & $(3.56-13.29)$ \\
\hline Lymphocyte count $\left(\times 10^{9} \Gamma^{1}\right)$ & 0.5 & $(0.299-0.927)$ \\
\hline Plt count $\left(\times 10^{4} \mathrm{~mm}^{-3}\right)$ & 17.8 & $(11.5-26.5)$ \\
\hline Fibrinogen (mg/dL) & 609.0 & $(378-711)$ \\
\hline Survival (dead) (\%) & 26.0 & $(31.3)$ \\
\hline AKI $(\%)$ & 38.0 & $(45.8)$ \\
\hline ARDS (\%) & 13.0 & $(15.7)$ \\
\hline Shock (\%) & 48.0 & $(57.8)$ \\
\hline DIC (\%) & 30.0 & $(36.1)$ \\
\hline Presepsin on Day 1 (pg/mL) & 1051.5 & $(569-1819.3)$ \\
\hline Presepsin on Day 2 (ng/mL) & 1016.5 & $(538-2156)$ \\
\hline Presepsin on Day $3(\mathrm{ng} / \mathrm{mL})$ & 802.0 & $(480.5-1825)$ \\
\hline Presepsin on Day 5 (ng/mL) & 1043.0 & $(480-1616)$ \\
\hline$\Delta$ Presepsin Day 2 - Day $1(\mathrm{pg} / \mathrm{mL})$ & -21.50 & $(-246.5-274.75)$ \\
\hline$\Delta$ Presepsin Day 3 - Day $1(\mathrm{pg} / \mathrm{mL})$ & -38.50 & $(-748.5-304)$ \\
\hline$\Delta$ Presepsin Day 5 - Day $1(\mathrm{pg} / \mathrm{mL})$ & -59.50 & $(-745.75-635.5)$ \\
\hline GPS & 1.0 & $(1-2)$ \\
\hline NLR & 12.6 & $(4.53-26.35)$ \\
\hline PLR & 321.9 & $(195.63-543.69)$ \\
\hline PI & 1.0 & $(1-2)$ \\
\hline PNI & 26.6 & $(21.26-33.72)$ \\
\hline SOFA & 8.0 & $(5-11)$ \\
\hline qSOFA & 2.0 & $(1-3)$ \\
\hline
\end{tabular}

CRP, C-reactive protein; WBC, white blood cell; AKI, acute kidney injury; ARDS, acute respiratory distress syndrome; DIC, disseminated intravascular coagulation; GPS, Glasgow Prognostic Score; NLR, neutrophil to lymphocyte ratio; PLR, platelet to lymphocyte ratio; PI, Prognostic Index; PNI, Prognostic Nutritional Index; SOFA, Sequential Organ Failure Assessment; qSOFA, quick Sequential Organ Failure Assessment. 
Table 2. Receiver operating characteristic curve analysis

\begin{tabular}{|c|c|c|c|c|c|}
\hline Variable & AUC & Cut-off & $\mathrm{P}$ value & Sensitivity & Specificity \\
\hline \multicolumn{6}{|l|}{ 28-day mortality } \\
\hline Presepsin on Day $1(\mathrm{pg} / \mathrm{mL})$ & 0.81 & 1340.00 & $\mathrm{P}<0.001$ & 0.78 & 0.75 \\
\hline Presepsin on Day $2(\mathrm{pg} / \mathrm{mL})$ & 0.80 & 1163.00 & $\mathrm{P}<0.001$ & 0.91 & 0.67 \\
\hline Presepsin on Day $3(\mathrm{pg} / \mathrm{mL})$ & 0.91 & 1819.00 & $\mathrm{P}<0.001$ & 0.86 & 0.83 \\
\hline Presepsin on Day $5(\mathrm{pg} / \mathrm{mL})$ & 0.91 & 3011.00 & $\mathrm{P}<0.001$ & 0.86 & 1.00 \\
\hline$\Delta$ Presepsin Day 3 - Day $1(\mathrm{pg} / \mathrm{mL})$ & 0.72 & 680.00 & 0.071 & 0.57 & 0.92 \\
\hline PNI & 0.73 & 22.73 & 0.001 & 0.67 & 0.75 \\
\hline iPS-GPS & 0.72 & 1.00 & $\mathrm{P}<0.001$ & 1.00 & 0.47 \\
\hline iPS-NLR & 0.72 & 2.00 & 0.001 & 0.50 & 0.86 \\
\hline iPS-PLR & 0.73 & 1.00 & $\mathrm{P}<0.001$ & 0.94 & 0.41 \\
\hline \multicolumn{6}{|l|}{ 60-day mortality } \\
\hline Presepsin on Day $1(\mathrm{pg} / \mathrm{mL})$ & 0.78 & 1340.00 & $\mathrm{P}<0.001$ & 0.71 & 0.75 \\
\hline Presepsin on Day $2(\mathrm{pg} / \mathrm{mL})$ & 0.76 & 1163.00 & 0.002 & 0.85 & 0.67 \\
\hline Presepsin on Day $3(\mathrm{pg} / \mathrm{mL})$ & 0.83 & 1156.00 & $\mathrm{P}<0.001$ & 0.90 & 0.78 \\
\hline Presepsin on Day $5(\mathrm{pg} / \mathrm{mL})$ & 0.77 & 3011.00 & 0.027 & 0.67 & 1.00 \\
\hline iPS-NLR & 0.71 & 1.00 & 0.001 & 0.81 & 0.52 \\
\hline \multicolumn{6}{|l|}{ 90-day mortality } \\
\hline Presepsin on Day $1(\mathrm{pg} / \mathrm{mL})$ & 0.76 & 1340.00 & $\mathrm{P}<0.001$ & 0.65 & 0.75 \\
\hline Presepsin on Day $2(\mathrm{pg} / \mathrm{mL})$ & 0.73 & 1163.00 & 0.004 & 0.73 & 0.66 \\
\hline Presepsin on Day $3(\mathrm{pg} / \mathrm{mL})$ & 0.83 & 1156.00 & $\mathrm{P}<0.001$ & 0.91 & 0.81 \\
\hline Presepsin on Day $5(\mathrm{pg} / \mathrm{mL})$ & 0.78 & 1399.00 & 0.011 & 0.70 & 0.79 \\
\hline \multicolumn{6}{|l|}{ 180-day mortality } \\
\hline Presepsin on Day $1(\mathrm{pg} / \mathrm{mL})$ & 0.77 & 1336.00 & $\mathrm{P}<0.001$ & 0.68 & 0.75 \\
\hline Presepsin on Day $2(\mathrm{pg} / \mathrm{mL})$ & 0.75 & 1163.00 & $\mathrm{P}<0.001$ & 0.76 & 0.69 \\
\hline Presepsin on Day $3(\mathrm{pg} / \mathrm{mL})$ & 0.85 & 1156.00 & $\mathrm{P}<0.001$ & 0.92 & 0.83 \\
\hline Presepsin on Day $5(\mathrm{pg} / \mathrm{mL})$ & 0.78 & 1313.00 & 0.006 & 0.73 & 0.74 \\
\hline$\Delta$ Presepsin Day 3 - Day $1(\mathrm{pg} / \mathrm{mL})$ & 0.73 & 390.00 & 0.010 & 0.58 & 0.91 \\
\hline iPS-GPS & 0.71 & 1.00 & $\mathrm{P}<0.001$ & 0.96 & 0.51 \\
\hline
\end{tabular}

AUC, area under the curve; PNI, Prognostic Nutritional Index; iPS, inflammation-Presepsin Score; GPS, Glasgow Prognostic Score; NLR, neutrophil to lymphocyte ratio; PLR, platelet to lymphocyte ratio 
Table 3. Log-rank test (all presepsin and variables for which $\mathrm{P}<0.05$ are shown)

\begin{tabular}{|c|c|}
\hline Variable & $\mathrm{P}$ value \\
\hline \multicolumn{2}{|l|}{ 28-day mortality } \\
\hline Presepsin on Day $1(\mathrm{pg} / \mathrm{mL})$ & 0.00 \\
\hline Presepsin on Day $2(\mathrm{pg} / \mathrm{mL})$ & 0.006 \\
\hline Presepsin on Day $3(\mathrm{pg} / \mathrm{mL})$ & 0.012 \\
\hline Presepsin on Day $5(\mathrm{pg} / \mathrm{mL})$ & 0.000 \\
\hline$\Delta$ Presepsin Day 2 - Day $1(\mathrm{pg} / \mathrm{mL})$ & 0.025 \\
\hline$\Delta$ Presepsin Day 3 - Day $1(\mathrm{pg} / \mathrm{mL})$ & 0.012 \\
\hline PNI & 0.002 \\
\hline iPS-GPS & 0.001 \\
\hline iPS-NLR & 0.001 \\
\hline iPS-PI & 0.008 \\
\hline iPS-PLR & 0.007 \\
\hline \multicolumn{2}{|l|}{ 60-day mortality } \\
\hline Presepsin on Day $1(\mathrm{pg} / \mathrm{mL})$ & 0.001 \\
\hline Presepsin on Day $2(\mathrm{pg} / \mathrm{mL})$ & 0.007 \\
\hline Presepsin on Day $3(\mathrm{pg} / \mathrm{mL})$ & 0.002 \\
\hline Presepsin on Day $5(\mathrm{pg} / \mathrm{mL})$ & 0.000 \\
\hline$\Delta$ Presepsin Day 2 - Day $1(\mathrm{pg} / \mathrm{mL})$ & 0.002 \\
\hline$\Delta$ Presepsin Day 3 - Day $1(\mathrm{pg} / \mathrm{mL})$ & 0.018 \\
\hline PNI & 0.004 \\
\hline iPS-GPS & 0.001 \\
\hline iPS-NLR & 0.007 \\
\hline iPS-PI & 0.027 \\
\hline iPS-PLR & 0.000 \\
\hline \multicolumn{2}{|l|}{ 90-day mortality } \\
\hline Presepsin on Day $1(\mathrm{pg} / \mathrm{mL})$ & 0.001 \\
\hline Presepsin on Day $2(\mathrm{pg} / \mathrm{mL})$ & 0.039 \\
\hline Presepsin on Day $3(\mathrm{pg} / \mathrm{mL})$ & 0.001 \\
\hline Presepsin on Day $5(\mathrm{pg} / \mathrm{mL})$ & 0.017 \\
\hline$\Delta$ Presepsin Day 2 - Day $1(\mathrm{pg} / \mathrm{mL})$ & 0.014 \\
\hline PNI & 0.004 \\
\hline iPS-GPS & 0.001 \\
\hline iPS-NLR & 0.008 \\
\hline iPS-PI & 0.106 \\
\hline iPS-PLR & 0.035 \\
\hline \multicolumn{2}{|l|}{ 180-day mortality } \\
\hline Presepsin on Day $1(\mathrm{pg} / \mathrm{mL})$ & 0.001 \\
\hline Presepsin on Day $2(\mathrm{pg} / \mathrm{mL})$ & 0.011 \\
\hline Presepsin on Day $3(\mathrm{pg} / \mathrm{mL})$ & 0.000 \\
\hline Presepsin on Day $5(\mathrm{pg} / \mathrm{mL})$ & 0.057 \\
\hline$\Delta$ Presepsin Day 2 - Day $1(\mathrm{pg} / \mathrm{mL})$ & 0.002 \\
\hline$\Delta$ Presepsin Day 3 - Day $1(\mathrm{pg} / \mathrm{mL})$ & 0.031 \\
\hline PNI & 0.005 \\
\hline iPS-GPS & 0.000 \\
\hline iPS-NLR & 0.012 \\
\hline iPS-PI & 0.048 \\
\hline iPS-PLR & 0.000 \\
\hline
\end{tabular}

PNI, Prognostic Nutritional Index; iPS, inflammation-Presepsin Score; GPS, Glasgow Prognostic Score; NLR, neutrophil to lymphocyte ratio; PI, Prognostic Index;

PLR, platelet to lymphocyte ratio 
Table 4. Predictors of mortality in sepsis patients (univariate analysis)

\begin{tabular}{|c|c|c|c|c|}
\hline & 28-day mortality & 60-day mortality & 90-day mortality & 180-day mortality \\
\hline & (non-survivors: $\mathrm{n}=19$ ) & (non-survivors: $\mathrm{n}=21$ ) & (non-survivors: $\mathrm{n}=23$ ) & (non-survivors: $\mathrm{n}=25$ ) \\
\hline Variable & $P$-value & $P$-value & $P$-value & $P$-value \\
\hline Age & 0.0590 & 0.1600 & 0.0679 & 0.1306 \\
\hline Sex & 0.7860 & 1.0000 & 1.0000 & 1.0000 \\
\hline Cancer & 0.4350 & 0.4500 & 0.4620 & 0.8110 \\
\hline Coronary artery disease & 0.2230 & 0.2640 & 0.3060 & 0.7950 \\
\hline Diabetes mellitus & 0.4410 & 0.4390 & 0.7190 & 0.7160 \\
\hline Hypertension & 0.7690 & 0.5680 & 1.0000 & 1.0000 \\
\hline Albumin & 0.4600 & 0.0115 & 0.0086 & 0.0102 \\
\hline CRP & 0.3890 & 0.8340 & 0.5550 & 0.3070 \\
\hline WBC & 0.6470 & 0.6870 & 0.3310 & 0.3740 \\
\hline Neutrophil & 0.5400 & 0.6710 & 0.3160 & 0.3330 \\
\hline Lymphocytes & 0.3420 & 0.5230 & 0.5790 & 0.5350 \\
\hline Platelet count & 0.0930 & 0.0749 & 0.0864 & 0.1070 \\
\hline Fibrinogen & 0.0289 & 0.0179 & 0.0186 & 0.0568 \\
\hline AKI & 0.0023 & 0.0037 & 0.0010 & 0.0012 \\
\hline ARDS & 0.0062 & 0.0021 & 0.0045 & 0.0160 \\
\hline Shock & 0.3190 & 0.1310 & 0.1520 & 0.2400 \\
\hline DIC & 0.0947 & 0.1860 & 0.4380 & 0.3170 \\
\hline Presepsin on Day 1 & 0.0005 & 0.0002 & 0.0003 & $\mathrm{P}<0.0001$ \\
\hline Presepsin on Day 2 & 0.0022 & 0.0047 & 0.0095 & 0.0025 \\
\hline Presepsin on Day 3 & 0.0006 & 0.0016 & 0.0010 & 0.0004 \\
\hline Presepsin on Day 5 & 0.0003 & 0.0152 & 0.0102 & 0.0084 \\
\hline$\Delta$ Presepsin Day 2 - Day 1 & 0.3490 & 0.5450 & 1.0000 & 0.5720 \\
\hline$\Delta$ Presepsin Day 3 - Day 1 & 0.2570 & 0.2680 & 0.1550 & 0.0648 \\
\hline$\Delta$ Presepsin Day 5 - Day 1 & 0.4600 & 0.8380 & 0.6370 & 0.6060 \\
\hline GPS & 0.3429 & 0.6315 & 0.3335 & 0.1520 \\
\hline NLR & 0.4665 & 0.5843 & 0.3345 & 0.2925 \\
\hline PLR & 0.8314 & 0.7299 & 0.6609 & 0.7056 \\
\hline PI & 0.5762 & 0.8809 & 0.4138 & 0.2652 \\
\hline PNI & 0.0028 & 0.0083 & 0.0063 & 0.0101 \\
\hline iPS-GPS & 0.0025 & 0.0052 & 0.0041 & 0.0012 \\
\hline PPS-NLR & 0.0019 & 0.0018 & 0.0032 & 0.0034 \\
\hline iPS-PLR & 0.0010 & 0.0026 & 0.0641 & 0.0125 \\
\hline iPS-PI & 0.0085 & 0.0321 & 0.0257 & 0.0107 \\
\hline iPS-PNI & 0.7106 & 0.3327 & 0.9109 & 0.8997 \\
\hline SOFA & 0.5933 & 0.2026 & 0.0809 & 0.1052 \\
\hline qSOFA & 0.5082 & 0.3257 & 0.1295 & 0.1876 \\
\hline
\end{tabular}

CRP, C-reactive protein; WBC, white blood cell; AKI, acute kidney injury, ARDS, acute respiratory distress syndrome; DIC, disseminated intravascular coagulation; GPS, Glasgow Prognostic Score; NLR, neutrophil to lymphocyte ratio; PLR, platelet to lymphocyte ratio; PI, Prognostic Index; PNI, Prognostic Nutritional Index;

iPS, inflammation-presepsin score; SOFA, Sequential Organ Failure Assessment; qSOFA, quick Sequential Organ Failure Assessment

Table 5. Predictors of mortality in sepsis patients (multivariate analysis)

\begin{tabular}{|c|c|c|c|c|}
\hline Variable & Odds ratio & \multicolumn{2}{|c|}{$95 \%$ CI } & $P$ value \\
\hline 28-day mortality & & & & \\
\hline Presepsin on Day 1 & 1.0025 & 1.00005 & 1.00497 & 0.046 \\
\hline 60-day mortality & & & & \\
\hline Presepsin on Day 1 & 1.0027 & 1.00025 & 1.00508 & 0.030 \\
\hline 90-day mortality & & & & \\
\hline Presepsin on Day 1 & 1.0027 & 1.00025 & 1.00508 & 0.030 \\
\hline & & & & \\
\hline 180-day mortality & & & & \\
\hline Presepsin on Day 1 & 1.0027 & 1.00025 & 1.00508 & 0.030 \\
\hline CI, confidence interval & & & & \\
\hline
\end{tabular}


Table 6. Receiver operating characteristic curve analysis (Presepsin on Day 1 for predicting early or late mortality)

\begin{tabular}{|c|c|c|c|c|c|}
\hline Variable & AUC & Cut-off & P value & Sensitivity & Specificity \\
\hline Presepsin on Day 1 (pg/mL) & & & & & \\
\hline & & & & 0.89 \\
\hline Death within 7 days of ICU admission & 0.84 & 1373.00 & 0.00002 & 0.77 \\
\hline Death after 7 days since ICU admission & 0.71 & 1152.00 & 0.00192 & 0.71 \\
\hline
\end{tabular}

AUC, area under the curve; ICU, intensive care unit.

Table 7. Receiver operating characteristic curve analysis (Inflammation-based prognostic scores, iPS, and SOFA for predicting early mortality)

\begin{tabular}{|c|c|c|c|c|c|}
\hline Variable & AUC & Cut-off & $\mathrm{P}$ value & Sensitivity & Specificity \\
\hline GPS & 0.56 & 2.00 & 0.5195 & 0.56 & 0.53 \\
\hline NLR & 0.61 & 37.62 & 0.3920 & 0.44 & 0.88 \\
\hline PLR & 0.52 & 356.94 & 0.8889 & 0.56 & 0.57 \\
\hline PI & 0.52 & 1.00 & 0.8319 & 0.89 & 0.30 \\
\hline PNI & 0.70 & 22.73 & 0.0809 & 0.67 & 0.77 \\
\hline iPS-GPS & 0.76 & 2.00 & 0.0045 & 0.56 & 0.91 \\
\hline iPS-NLR & 0.79 & 2.00 & 0.0000 & 0.56 & 0.88 \\
\hline iPS-PLR & 0.80 & 2.00 & 0.0000 & 0.44 & 0.93 \\
\hline iPS-PI & 0.74 & 1.00 & 0.0000 & 1.00 & 0.55 \\
\hline iPS-PNI & 0.59 & 2.00 & 0.3778 & 0.33 & 0.84 \\
\hline SOFA & 0.62 & 9.00 & 0.2205 & 0.67 & 0.57 \\
\hline qSOFA & 0.63 & 2.00 & 0.1425 & 0.78 & 0.46 \\
\hline
\end{tabular}

AUC, area under the curve; GPS, Glasgow Prognostic Score; NLR, neutrophil to lymphocyte ratio; PLR, platelet to lymphocyte ratio;

PI, Prognostic Index; PNI, Prognostic Nutritional Index; PS, inflammation-Presepsin score; SOFA, Sequential Organ Failure Assessment; qSOFA, quick Sequential Organ Failure Assessment. 
Table 8 . Univariate and multivariate analyses for predicting mortality in sepsis patients

\begin{tabular}{|c|c|c|c|c|}
\hline & Univariate analysis & \multicolumn{3}{|c|}{ Mulitivariate analysis } \\
\hline & & \multicolumn{2}{|c|}{ Odds Ratio } & \\
\hline Variable & P-value & \multicolumn{2}{|c|}{$(95 \% \mathrm{CI})$} & $P$-value \\
\hline Age & 0.7014 & & & \\
\hline Sex & 0.4689 & & & \\
\hline Cancer & 0.2971 & & & \\
\hline Coronary artery disease & 0.2559 & & & \\
\hline Diabetes mellitus & 1.0000 & & & \\
\hline Hypertension & 0.4358 & & & \\
\hline Albumin & 0.0852 & & & \\
\hline CRP & 0.8591 & & & \\
\hline WBC & 0.5499 & & & \\
\hline Neutrophil & 0.3952 & & & \\
\hline Lymphocytes & 0.3849 & & & \\
\hline Platelet count & 0.1556 & & & \\
\hline Fibrinogen & 0.0011 & & & \\
\hline AKI & 0.0360 & & & \\
\hline ARDS & 0.0706 & & & \\
\hline Shock & 0.0708 & & & \\
\hline DIC & 0.2678 & & & \\
\hline Presepsin on Day 1 & 0.0012 & 1.0007 & $(1.0001-1.0013)$ & 0.0320 \\
\hline GPS & 0.5366 & & & \\
\hline NLR & 0.3051 & & & \\
\hline PLR & 0.8792 & & & \\
\hline PI & 0.8695 & & & \\
\hline PNI & 0.0527 & & & \\
\hline iPS-GPS & 0.0057 & & & \\
\hline iPS-NLR & 0.0020 & & & \\
\hline iPS-PLR & 0.0016 & & & \\
\hline iPS-PI & 0.0096 & & & \\
\hline iPS-PNI & 0.3112 & & & \\
\hline SOFA & 0.2644 & & & \\
\hline qSOFA & 0.2120 & & & \\
\hline \multicolumn{5}{|c|}{ CRP, C-reactive protein; WBC, white blood cell; AKI, acute kidney injury; ARDS, acute respiratory distress syndrome; } \\
\hline \multicolumn{5}{|c|}{ DIC, disseminated intravascular coagulation; GPS, Glasgow Prognostic Score; NLR, neutrophil to lymphocyte ratio; } \\
\hline \multicolumn{5}{|c|}{ PLR, platelet to lymphocyte ratio; PI, Prognostic Index; PNI, Prognostic Nutritional Index; iPS, inflammation-presepsin } \\
\hline \multicolumn{5}{|c|}{ score; SOFA, Sequential Organ Failure Assessment; qSOFA, quick Sequential Organ Failure Assessment. } \\
\hline
\end{tabular}

\section{Figures}


a
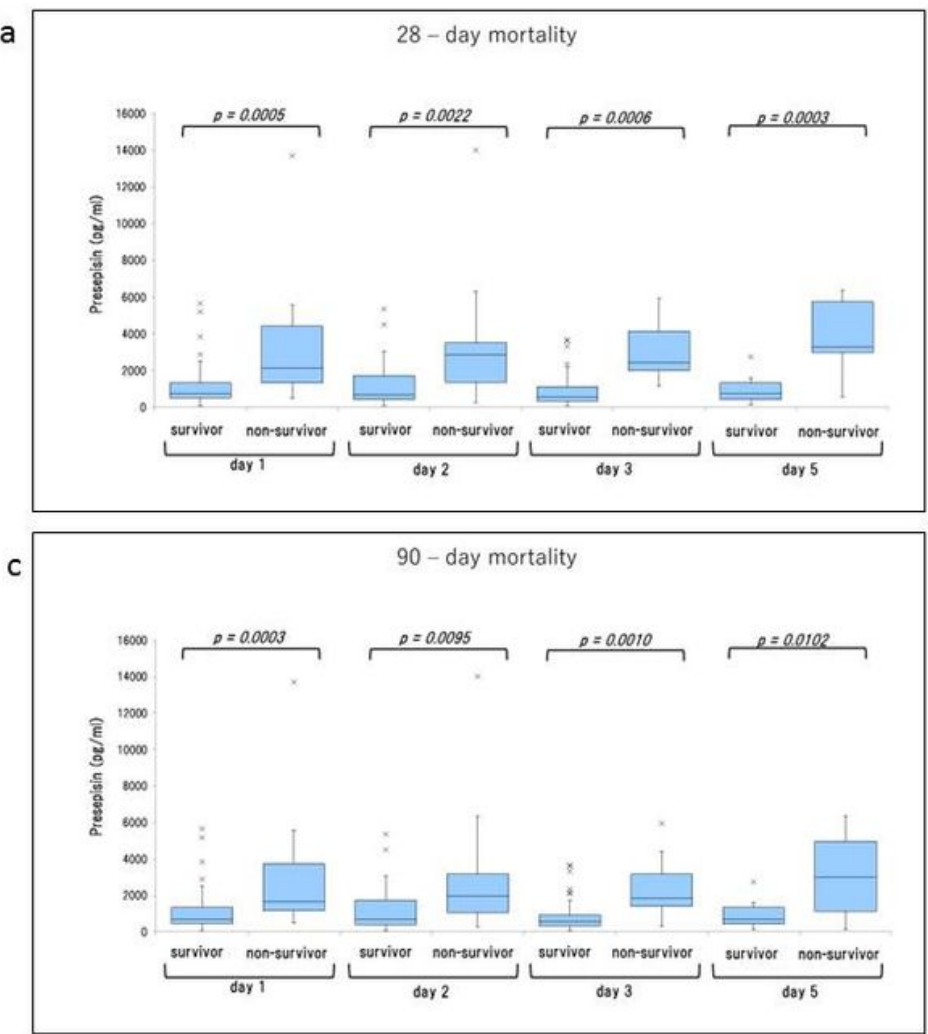

b

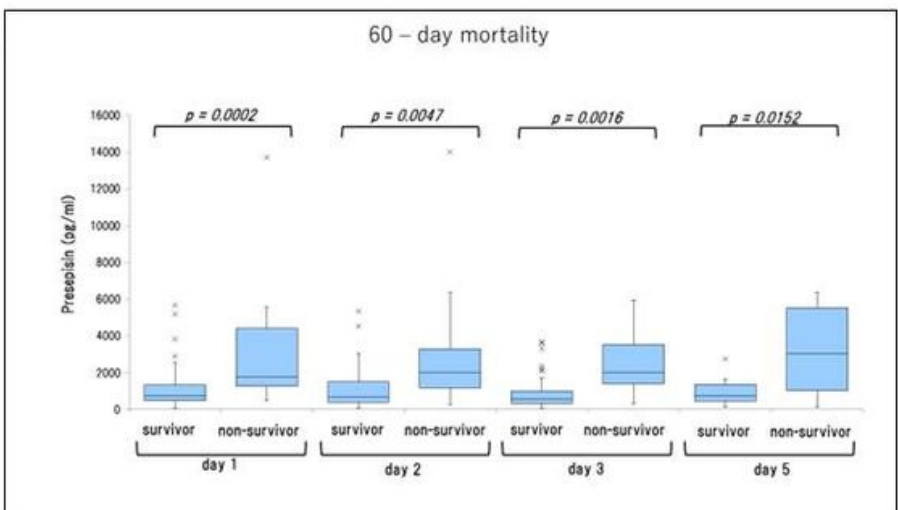

d

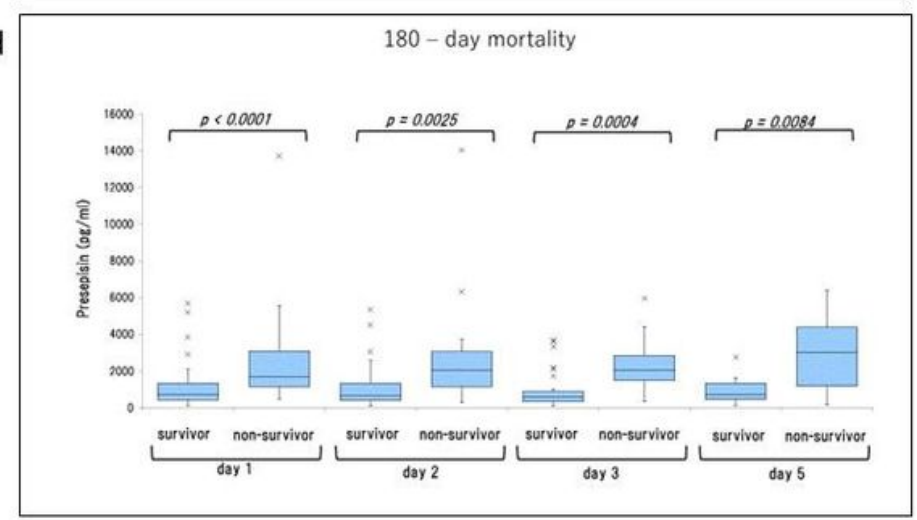

\section{Figure 1}

Comparison of presepsin values between sepsis survivors and non-survivors. (a) 28-day mortality, (b) 60day mortality, (c) 90-day mortality, and (d) 180-day mortality. 


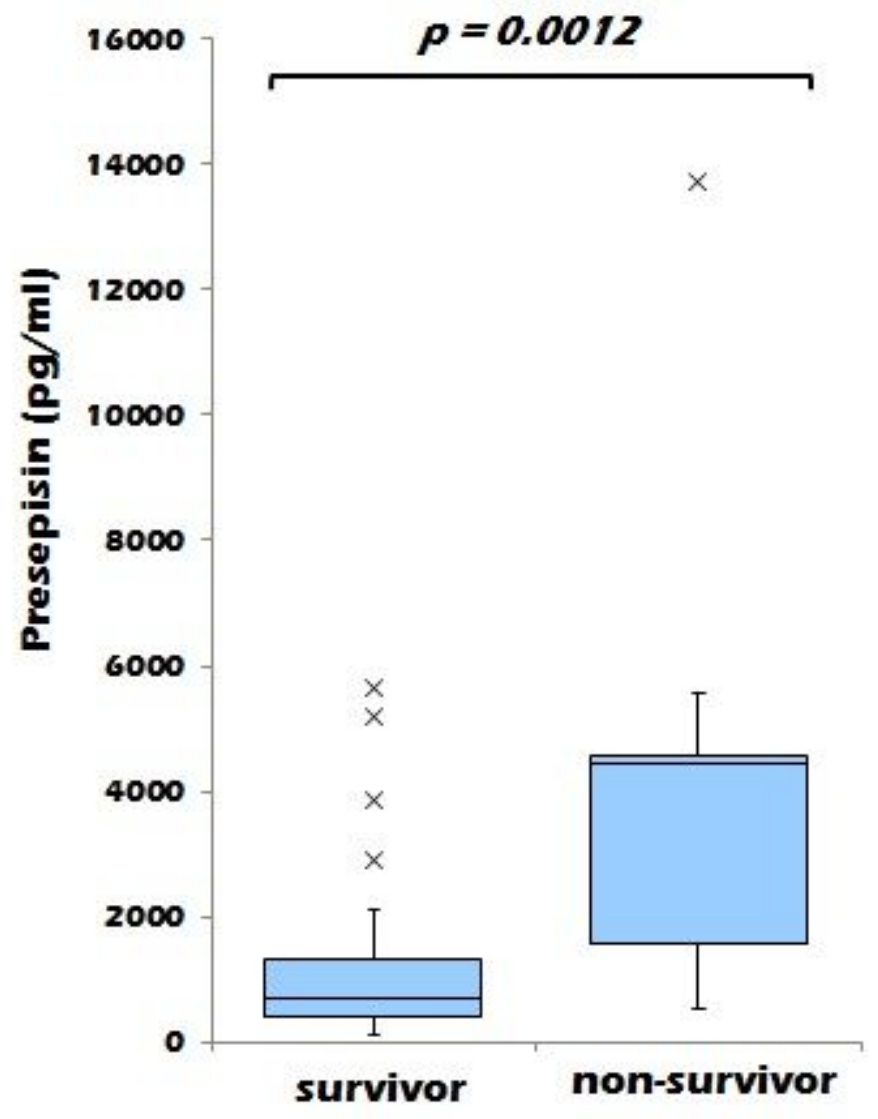

Figure 2

Comparison of presepsin values (Day 1 ) for predicting early mortality in sepsis survivors versus nonsurvivors. 


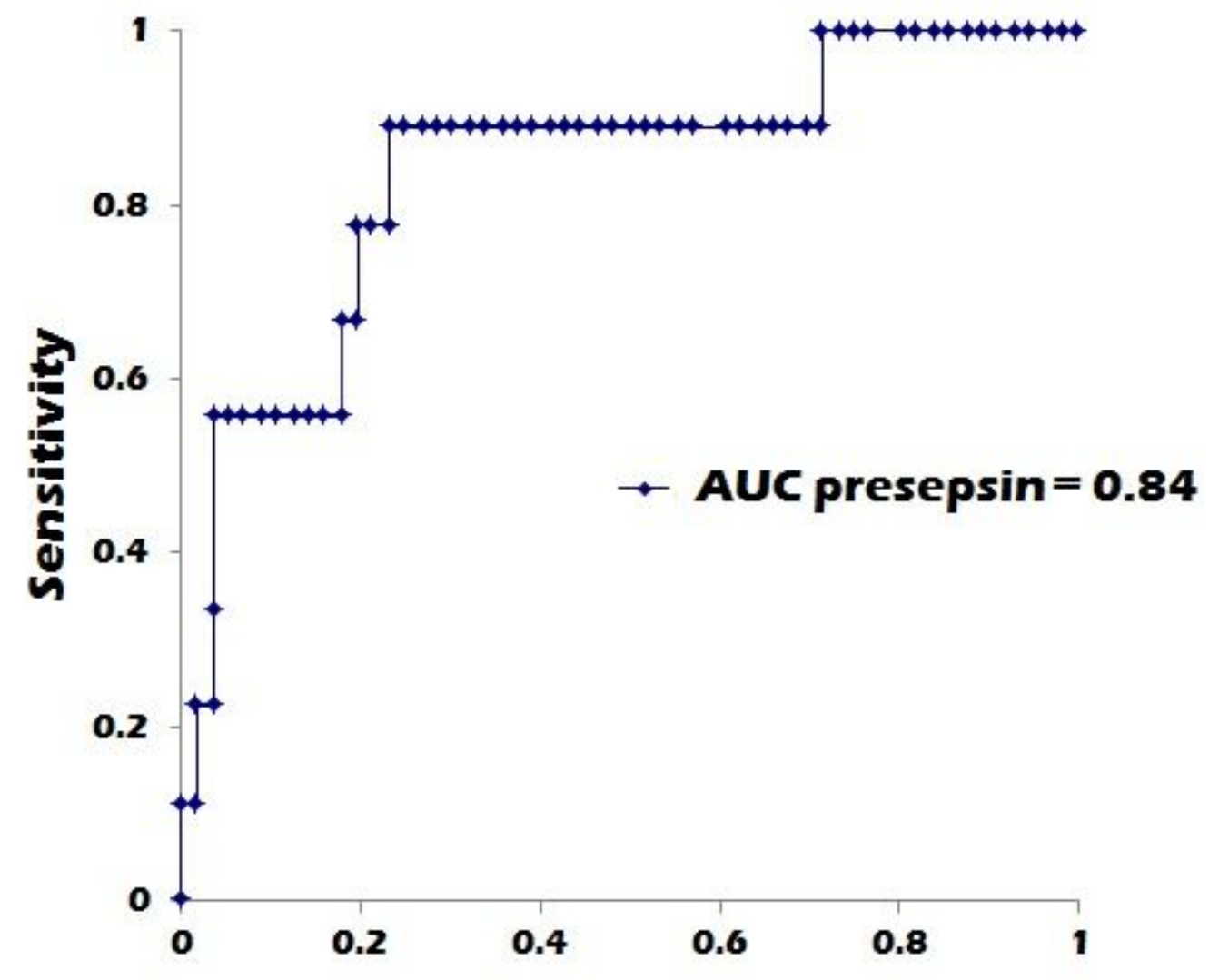

Figure 3

ROC analysis of presepsin values on Day 1 for predicting early mortality. 